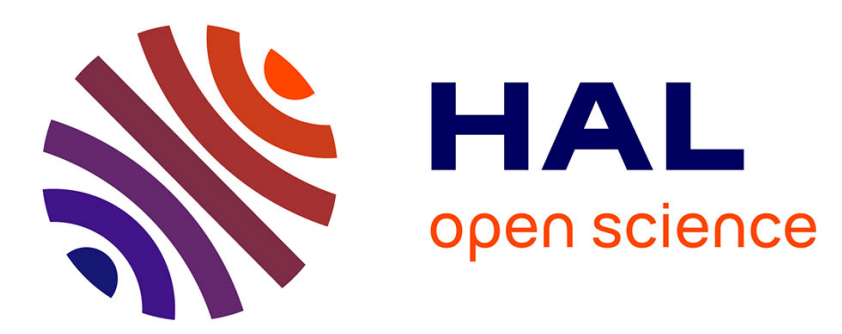

\title{
Multiscale transmissivity study of drain-tube planar geocomposites: effect of experimental device on test representativeness
}

\author{
S. Bourgès-Gastaud, Eric Blond, Nathalie Touze-Foltz
}

\section{- To cite this version:}

S. Bourgès-Gastaud, Eric Blond, Nathalie Touze-Foltz. Multiscale transmissivity study of draintube planar geocomposites: effect of experimental device on test representativeness. Geosynthetics International, 2013, 20 (3), p. 119 - p. 128. 10.1680/gein.13.00006 . hal-00857381

\section{HAL Id: hal-00857381 \\ https://hal.science/hal-00857381}

Submitted on 3 Sep 2013

HAL is a multi-disciplinary open access archive for the deposit and dissemination of scientific research documents, whether they are published or not. The documents may come from teaching and research institutions in France or abroad, or from public or private research centers.
L'archive ouverte pluridisciplinaire HAL, est destinée au dépôt et à la diffusion de documents scientifiques de niveau recherche, publiés ou non, émanant des établissements d'enseignement et de recherche français ou étrangers, des laboratoires publics ou privés. 


\title{
Multiscale transmissivity study of drain-tube planar geocomposites: effect of experimental device on test representativeness
}

\author{
S. Bourgès-Gastaud ${ }^{1}$, E. Blond ${ }^{2}$ and N. Touze-Foltz ${ }^{3}$ \\ ${ }^{1}$ PhD Student, Irstea, HBAN research unit, 1, rue Pierre-Gilles de Gennes, 92761 Antony Cedex, \\ France, Telephone: +3314096 62 14, Telefax: +33140966270, E-mail: sebastien.gastaud@irstea.fr \\ ${ }^{2}$ SAGEOS Manager, CTT group Vice-president, 3000, rue Boullé, Saint-Hyacinthe, QC, Canada J2S \\ 1H9, Telephone: +1 450778 1870, Telefax: +1 450778 3901, E-mail: eblond@gcttg.com \\ ${ }^{3}$ Research director, INEGE team, Irstea, HBAN research unit, 1, rue Pierre-Gilles de Gennes, 92761 \\ Antony Cedex, France, Telephone: +33 1409660 39, Telefax: +33 140966 270, \\ E-mail: nathalie.touze@irstea.fr
}

Received 1 June 2012, revised 25 January 2013, accepted 29 January 2013

\begin{abstract}
Hydraulic transmissivity is the most important design parameter of geocomposites used for in-plane drainage applications. This paper presents an in-depth investigation of the hydraulic behaviour of drain-tube planar geocomposites (DTPGs) and characterises the locations and causes of head losses based on a multiscale experimental approach using three different apparatus. In particular, a transmissivity rig that accommodates specimens up to $1 \mathrm{~m}^{2}$ was developed to define the minimum representative surface area required to characterise DTPGs. The experimental data acquired in this study support a theoretical relationship linking head losses that occur within DPTGs to flow rate. This relationship is used to analyse the results obtained with other transmissivity rigs and to identify the key locations where head losses develop. In addition, evidence that Colebrook's equation can be applied to corrugated tubes is presented. Based on this study, it is concluded that the measured DTPG transmissivity is significantly affected by specimen length and by the experimental device used to make the measurement. For example, the DTPG transmissivity measured in accordance with ASTM D4716-08 was found to be 14\% lower than the actual DTPG transmissivity.
\end{abstract}

KEYWORDS: Geosynthetics, Drainage geocomposite, Transmissivity, Discharge capacity, Corrugated tube, Singular head loss, Colebrook's equation, Drain-tube, DTPG

REFERENCE: Bourgès-Gastaud, S., Blond, E. \& Touze-Foltz, N. (2013). Multiscale transmissivity study of drain-tube planar geocomposites: effect of experimental device on test representativeness. Geosynthetics International, 20, No. 3, 119-128. [http://dx.doi.org/10.1680/gein.13.00006]

\section{INTRODUCTION}

Drainage geocomposites are widely used in environmental applications to collect liquid from facilities such as landfills, roadway embankments or earth dams. A geocomposite consists of a combination of different types of geosynthetics (geotextiles, tubes, geonets, geogrids, etc.). Applications for geocomposites are increasingly numerous for several reasons, but in particular because combining the attributes of several different materials leads to higher performance (Koerner 1997). For example, drainage geocomposites can collect leachate at the base of landfills or, by dissipating pore water pressure, they can improve the bearing capacity of soils (Bordier and Zimmer 2000; Palmeira and Gardoni 2002). Of all the drainage geocomposites, drain-tube planar geocomposites (DTPGs) have gained acceptance within the engineering community as the material of choice for transporting liquids and gases (Saunier et al. 2010) because of the reliability of the perforated tubes, which are regularly spaced in a DTPG and provide high in-plane flow capacity. These tubes are embedded into two non-woven needle-punched polypropylene geotextiles: one acts as a filter, the other as a drainage layer, and the two geotextiles together provide a separation function (Giroud et al. 2000). Furthermore, thick geotextiles can also act as a cushion layer to protect the underlying geomembrane from puncture (Touze-Foltz 2002).

Drainage geocomposites are typically designed to optimise their in-plane flow capacity and with consideration for their site-specific design loads and boundary conditions. The design parameter used to quantify this flow 
capacity is either the flow rate per unit width under a specific hydraulic gradient, or the hydraulic transmissivity (hereafter simply transmissivity), which is defined as

$$
\theta=\frac{Q}{i}=\frac{Q L}{\Delta H}
$$

where $\theta$ is the transmissivity, $Q$ is the flow rate per unit width, $i$ is the hydraulic gradient, $\Delta H$ is the head loss, and $L$ is the length.

From Equation 1, transmissivity is the ratio of flow rate to hydraulic gradient. Standard calculation techniques consider that the transmissivity is only valid for laminarflow conditions (ISO 12958:2010; ISO 2010), that is, when Darcy's law is valid, and the transmissivity is often presented in geosynthetic design as an intrinsic property of the product, thus not dependent on external conditions such as the hydraulic gradient. According to this paradigm, transmissivity should be constant. However, the transmissivity of a product is not a true constant but is always associated not only with the normal load but also with the hydraulic gradient. In fact, transmissivity decreases as the hydraulic gradient increases, because of the development of turbulence within the water circulation path. Generally, for hydraulic gradients typically used in transmissivity tests, the flow is non-laminar for geonets or geocomposites (Giroud et al. 2012). Therefore, the water conductivity characteristic of geocomposites can be better expressed as a discharge (flow rate) for a given hydraulic loss (van der Sluys and Dierickx 1987) than as a transmissivity. Accordingly, in the simulations, the 'transmissivity' value as defined by ASTM D4716-08 or ISO 12958:2010 was not used; instead, the calculation was based on the direct expression of the flow rate as a function of head loss.

The drainage capability of DTPGs comes from corrugated tubes regularly spaced along the width of the DTPG (see Figure 1). The number of tubes per metre (typically 1 to 4) and their diameter $(16,20$ or $25 \mathrm{~mm})$ can be modified depending on the requirements of the project. To allow fluid to enter the tube from the soil and the geotextile, the tubes are perforated along four lines travelling the length of the tube, with the lines spaced $90^{\circ}$ apart around the tube circumference (Bourgès-Gastaud et al. 2012). The majority of DTPG drainage capability is provided by these corrugated tubes (Faure et al. 1993).

A major difference between DTPGs and other geocomposites is that the DTPG structure leads to a large difference between the hydraulic conductivity of the geotextile and that of the tubes. Shortly after DTPGs were invented, Faure et al. (1993) warned engineers that the non-homogeneous drainage structure of DTPGs means that they cannot be designed using the rules that apply to other planar-drainage geosynthetics, such as those with a geonet core. Therefore, to treat the flow within DTPGs, a theory was developed that considers both the transmissivity of the geotextile and the discharge capacity of the tubes. The transmissivity and the discharge must be dissociated because Darcy's law cannot be used in tubes, in contrast to geotextiles where the flow can be considered to be laminar. Unfortunately, in spite of these twenty-year-

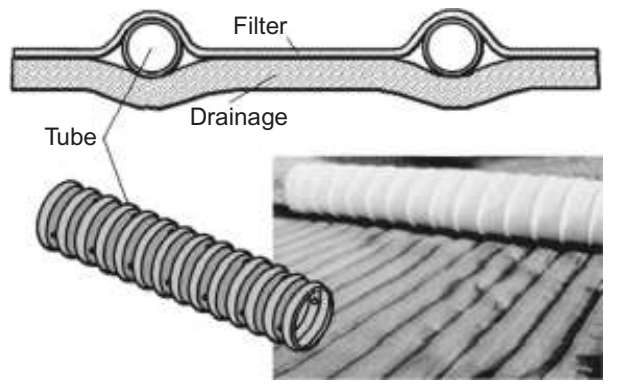

(a)

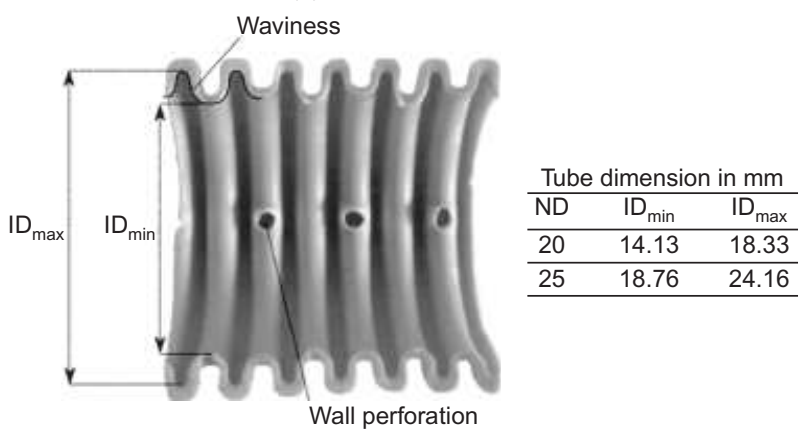

(b)

Figure 1. (a) Schematic diagram of DTPG; (b) cross-section of corrugated tube (ND is nominal diameter, ID is inner diameter)

old recommendations, transmissivity from standard tests is still being used to design DTPGs and to characterise and specify their hydraulic performance. In this paper, it is demonstrated that this approach is erroneous by comparing the tube discharge capacity with the transmissivity of the whole product. This analysis is based on data gathered from three experimental devices and on a numerical analysis that reveals a relationship between head loss and flow rate. An in-depth investigation of the hydraulic behaviour of DTPGs is presented in which the head-loss locations and causes are identified based on a multiscale experimental approach employing three different apparatuses. Well-known hydraulic equations and concepts are also applied to analyse the results theoretically. The resulting model of head loss as a function of flow rate precisely describes the hydraulic behaviour of both the tube and the entire DTPG.

\section{MEASUREMENT OF TRANSMISSIVITY OF DRAIN-TUBE PLANAR GEOCOMPOSITES: MULTISCALE APPARATUS}

An experimental procedure was designed to analyse hydraulic properties on three successive scales spanning from a single tube to a representative DTPG surface area of $1 \mathrm{~m}^{2}$. A typical ASTM transmissivimeter (StdT) was used in addition to two new apparatuses, which were designed to improve the understanding of the in-plane discharge capacity. Each apparatus analyses the DTPG from a different point of view: (i) pressure taps directly plugged into the tube allow characterisation the DTPG base element (i.e., the tubes), and (ii) a large-scale 
transmissivimeter (LST) allows testing of the representative surface area of the DTPG (a $1 \mathrm{~m}$ square).

\subsection{Tube discharge capacity}

A classic device was used to measure the discharge capacity of the DTPG base elements (i.e., the tubes). Water was directly injected from a smooth-walled tube into a $0.7 \mathrm{~m}$-long corrugated tube of identical diameter that is, no change in hydraulic section - so fluid velocity remained constant. To avoid singular head loss at both the inlet and outlet, the tube outlet evacuated the water directly into the atmosphere. One wall pressure tap was plugged directly into the tube near the inlet to measure the upstream hydraulic head. The downstream hydraulic head corresponds to the water height at mid-diameter of the corrugated tube. By taking the difference between the upstream and downstream heads, the head loss for a known flow rate is obtained. These tests were conducted in the testing laboratory of Irstea (Antony, France) with two different tubes (nominal diameter D20 and D25; see Figure 1b) traditionally used in DTPGs.

\subsection{Standard transmissivimeter}

The standard transmissivimeter (StdT, from Geopro, PA, USA) could test specimens $0.305 \mathrm{~m}$ wide by $0.355 \mathrm{~m}$ long (see Figure 2). This test was conducted in the Geosynthetics Technology Centre at Sageos (Saint-Hyacinthe, QC, Canada) according to ASTM D4716-08 and ISO 12958:2010 with the following modifications.

- $\quad$ The DTPG was installed on a bedding of $25 \mathrm{~mm}$ of fine sand.

- $\quad$ The DTPG was covered by $75 \mathrm{~mm}$ of fine sand.

- One test specimen was used instead of two (three) for ASTM D4716-08 (ISO 2010).

All values were corrected for water temperature and, when the water head exceeded $0.1 \mathrm{~m}$, the normal stress was corrected for the excess. The effect of leaking on transmissivity has been demonstrated many times, and both ASTM and ISO standards recommend that leakage not exceed $10 \%$ for low flow rates. However, leaks are intrinsically hard to quantify and may lead to misleading performance predictions or excessively conservative design. To limit leaks both in StdT and in LST, stress was applied on the DTPG by fine sand; this deformable

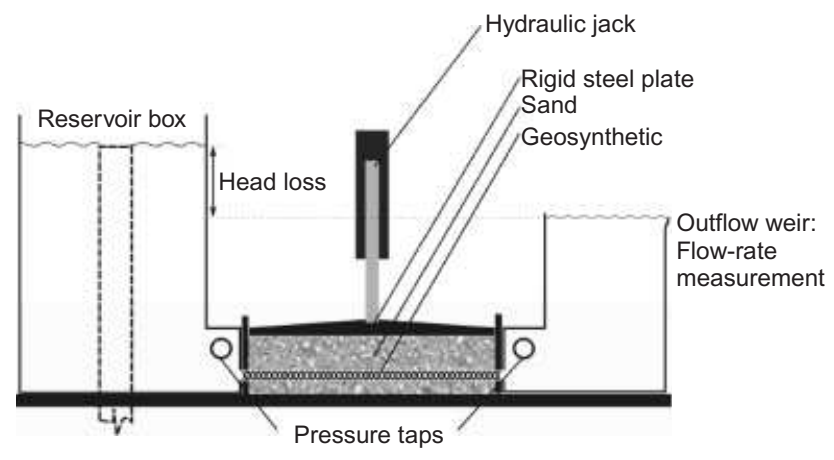

Figure 2. Schematic of a standard transmissivimeter material limits leaks. Using Darcy's law, all values of flow rate are corrected by the amount of water flowing in the sand (the coefficient of permeability of sand, $k_{\mathrm{s}}=5 \times 10^{-5} \mathrm{~m} / \mathrm{s}$, is taken from the product datasheet).

\subsection{Large-scale transmissivimeter}

Zimmel et al. (2011) showed that specimen size can significantly affect standard transmissivity tests. Using either ASTM D4716-08 or ISO 12958:2010, transmissivity measurements were performed with a small-scale apparatus (at most $0.305 \mathrm{~m}$ wide). This size is insufficient to evaluate DTPGs with tube spacing greater than $0.305 \mathrm{~m}$, so the transmissivity of these specimens must be estimated by making assumptions that may be controversial. For example, how is the result of a measurement made on a $0.2 \mathrm{~m}$-wide specimen extrapolated to a specimen with a representative width of $1 \mathrm{~m}$ when the water is mainly conducted by the central tube? Part of the solution to this problem of upscaling is provided by a specially designed LST, which is unique in that it satisfies the representative elementary surface area criterion for DTPGs. In other words, this LST makes it possible to test a $1 \mathrm{~m}^{2}$ specimen, which is the smallest size representative of the whole product when tube spacing reaches $1 \mathrm{~m}$. The LST is based on the same model as the StdT (see Figure 3).

The LST maintains constant head loss for hydraulic gradients ranging from 0.005 to 1 . The geocomposite is sandwiched between a lower layer of fine sand $25 \mathrm{~mm}$ thick and an upper layer of fine sand $75 \mathrm{~mm}$ thick. The load, which can reach up to $200 \mathrm{kPa}$, is applied by a hydraulic ram pressing on a $1 \mathrm{~m}^{2}$ metallic frame. The precision of the loading mechanism is estimated to be in the range of $5-10 \%$, although the precision is not considered to be a critical issue since Bourgès-Gastaud et al. (2012) showed that compressive stress up to $2 \mathrm{MPa}$ $\left(\sim 200 \mathrm{t} / \mathrm{m}^{2}\right)$ does not affect the transmissivity of DTPG sandwiched by layers of sand.

Thus, these tests were conducted in general accordance with both ASTM D4716-08 and ISO 12958:2010.

Table 1 presents a summary of the experiment parameters. Each row in the table is considered to be equivalent in terms of hydraulic behaviour.

\section{SIMULATION OF TRANSMISSIVITY OF DRAIN-TUBE PLANAR GEOCOMPOSITES: NUMERICAL METHOD}

Head loss is the reduction in the total head of the fluid as it moves through a fluid system. Head loss is unavoidable in real fluids and is usually classified into two categories as

- linear head loss due to friction against the tube wall

- singular head loss due to the singularities such as tees, widenings, or valves.

Experimental results from the three apparatuses ensured a reliable base from which the numerical calculation of the head loss through a DTPG can be calibrated. Hydrau- 


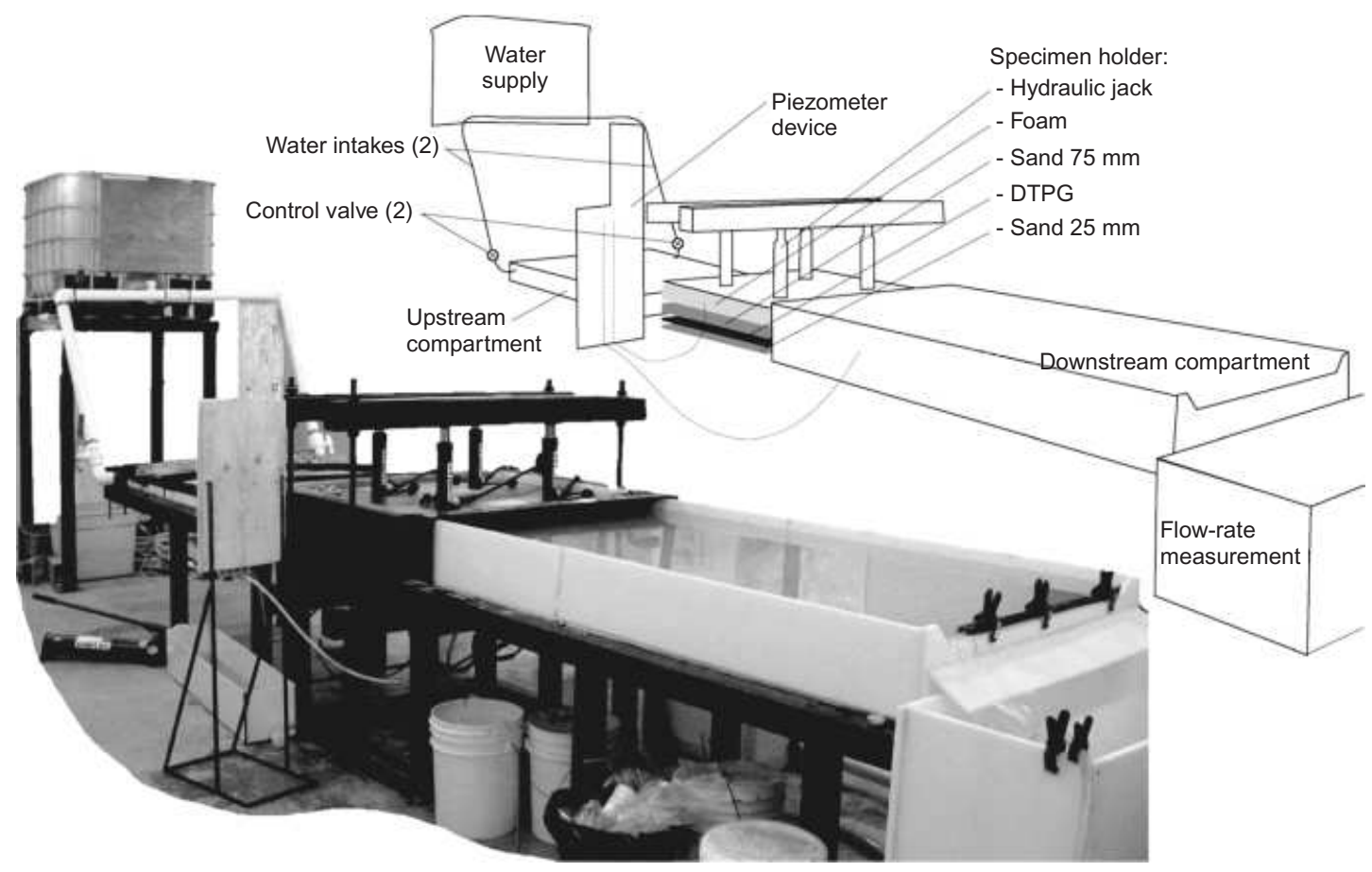

Figure 3. Photograph and schematic of the LST

Table 1. Summary of experiment parameters

\begin{tabular}{|l|l|l|c|c|c|}
\hline & Device & $\begin{array}{c}\text { Length } \\
(\mathrm{m})\end{array}$ & Stress $(\mathrm{kPa})$ & $\begin{array}{c}\text { Number } \\
\text { of tubes }\end{array}$ & $\begin{array}{c}\text { Number } \\
\text { of data }\end{array}$ \\
\hline \multirow{2}{*}{ D20 } & Tube only & 0.7 & - & 1 & 20 \\
& StdT & 0.305 & $20,100,200$ & 1 & 12 \\
& LST & 0.25 & 100 & 4 & 3 \\
& 0.5 & 100 & 4 & 4 \\
& & 1 & $20,100,200$ & 4 & 12 \\
D25 & Tube only & 0.7 & - & 1 & 33 \\
& StdT & 0.305 & $20,100,200$ & 1 & 12 \\
& LST & 0.25 & 100 & $1,2,4$ & 9 \\
& & 0.5 & 100 & $1,2,4$ & 12 \\
& & 1 & $20,100,200$ & $1,2,4$ & 48 \\
\hline
\end{tabular}

lic concepts and laws are used to describe the transmissivity and to thoroughly analyse DTPG discharge capacity.

\subsection{Linear head loss}

Linear head loss occurs throughout the length of the tube because of the friction experienced by a Newtonian liquid flowing in the tube. The following empirical DarcyWeisbach equation relates head loss due to friction along a given length of tube to average fluid-flow velocity (Romeo et al. 2002)

$$
\Delta H_{\text {lin }}=\lambda \frac{L V_{\mathrm{t}}^{2}}{D 2 g}
$$

where $\Delta H_{\text {lin }}$ is the linear head loss, $\lambda$ is the dimensionless friction factor, $L$ is the tube length, $D$ is the tube diameter, $g$ is the standard acceleration due to gravity, and $V_{\mathrm{t}}$ is the average fluid velocity in the tubes.

To use Equation 2, a theoretical approach to calculating the friction factor $\lambda$ is required that agrees with experimental results. Colebrook's equation (Colebrook 1939) is used for this purpose, based on Moody's demonstration of its applicability over a very wide range of Reynolds number and relative roughness (Moody 1944). In fact, the well-known Moody chart is a plot of solutions of Colebrook's equation. This equation, which is now the accepted standard of accuracy for calculated friction factors (Brkić 2011), is

$$
\frac{1}{\sqrt{\lambda}}=-2 \log \left(\frac{\varepsilon}{3.7 D}+\frac{2.51}{\operatorname{Re} \sqrt{\lambda}}\right)
$$

where $\varepsilon$ is the absolute roughness and Re is the dimensionless Reynolds number that characterises the capacity of a fluid to develop turbulence (Reynolds 1883).

Because it is implicit, Colebrook's equation cannot be rearranged to obtain the friction factor directly. To bypass this difficulty, several authors have proposed the more convenient approach of explicit approximations (Sonnad and Goudar 2006). In the present work, the solution developed by Serghides (1984) is employed.

Although Colebrook's equation is widely used to estimate the friction factor for turbulent fluid flow in rough tubes, to the best of the authors' knowledge, no proof is available that it applies to corrugated tubes. This geometry not only implies two different internal diameters ( ID $_{\min }$ and $\mathrm{ID}_{\max }$; see Figure 1), but also two types of roughness.

- Classic roughness described in the pioneering work of Nikuradse (1933) with sand-coated tubes. This roughness corresponds to the average diameter of sand grains and causes increased turbulence - that is, an increase of frictional loss. Commonly, the roughness of industrial tubes is in the range of a few micrometres. For DTPG tubes this roughness is due to the perforations of the wall and results in an average roughness of $100 \mu \mathrm{m}$. 
- The depth of the waves along the corrugated tube. This roughness is the difference between $\mathrm{ID}_{\max }$ and $\mathrm{ID}_{\min }$. The impact of the corrugated geometry on turbulence is unknown.

The aim of Section 4.1 is to determine the impact of these two types of roughness and evaluate which one prevails. Moreover, Colebrook's equation is traditionally used with fully turbulent flow $(\operatorname{Re}>3000)$. For the experiments described in this paper, a low Reynolds number of $\sim 1900$ was obtained for the lowest flow rate. However, Kandlikar et al. (2005) proved that, with an increase in roughness, the laminar-to-turbulent transition occurs at lower Reynolds numbers. Thus, the corrugation waves can enlarge the domain of validity of Colebrook's equation. To ensure that Colebrook's equation is applicable to corrugated tubes, the tubes were tested to determine the effect of both the corrugated geometry and a low Reynolds number.

\subsection{Singular head loss}

The second category of head loss occurs when flow is perturbed, such as at a tee, a widening, or a bend. The perturbing singularity encountered by the fluid consists of sudden or gradual changes in the boundaries and results in a change in magnitude, direction, or distribution of the flow velocity. This singular head loss is determined by using Equation 4 (Fester et al. 2007)

$$
\Delta H_{\mathrm{s}}=k \frac{V_{\mathrm{t}}^{2}}{2 g}
$$

where $\Delta H_{\mathrm{s}}$ is the singular head loss and $k$ is the singular head loss factor, which is a property of each singularity.

The head losses arising from singularities are often referred to as 'minor' losses and are normally neglected when they represent less than $5 \%$ of the total linear head losses (Edwards et al. 1985). However, for short tubes, these 'minor' singular head losses can easily add up to exceed the linear head losses (Fester et al. 2007). Of all the singularities, the head loss due to narrowing is assumed to be negligible, whereas head loss due to widening is not. In fact, the latter can cause a large singular head loss due to the change in fluid velocity (see Figure 4). By using a global momentum budget (Euler theorem), the singular head loss was estimated over a domain that includes the singularity (Thual 2010) as follows

$$
\rho V_{\mathrm{up}}^{2} A_{\mathrm{up}}+H_{\mathrm{up}} A_{\mathrm{do}}=\rho V_{\mathrm{do}}^{2} A_{\mathrm{do}}+H_{\mathrm{do}} A_{\mathrm{do}}
$$

where $H_{\text {up }}$ is the upstream head, $H_{\text {do }}$ is the downstream head, $A_{\text {up }}$ is the upstream area, $A_{\text {do }}$ is the downstream area, and $\rho$ is the fluid density.

From Equation 5, the singular head loss along the widening is deduced

$$
\Delta H_{\mathrm{s}}=H_{\text {up }}-H_{\text {do }}=\frac{\left(V_{\text {do }}-V_{\text {up }}\right)^{2}}{2 g}
$$

\subsection{Which head losses occur in a transmissivimeter?}

When a DTPG is tested in a transmissivimeter, the drainage capacity of the DTPG is determined by its tubes. Neither the sand under load nor the nonwoven geotextile under load can conduct a significant amount of water. With these assumptions, a DTPG in a transmissivimeter can be represented by two compartments linked by one, two, or four tubes. The distribution of head loss along the DTPG is shown in Figure 5.

The total head loss $\Delta H_{\text {tot }}$ in a transmissivimeter is the sum of the linear head loss $\Delta H_{\text {lin }}$ and the singular head loss $\Delta H_{\mathrm{s}}$ that occurs at the outlet (the widening). The total head loss in the transmissivimeter is given by combining Equations 2 and 4, which gives

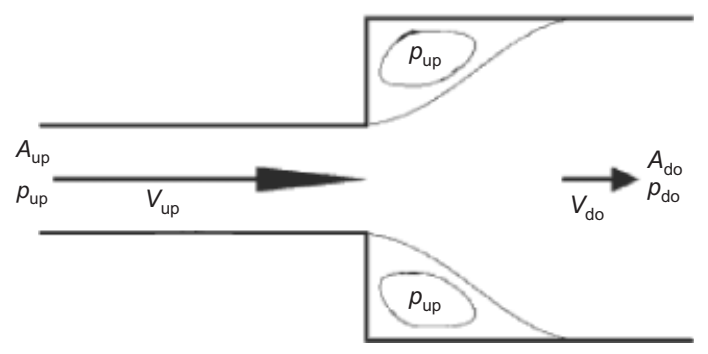

Figure 4. Sudden widening and pressure distribution

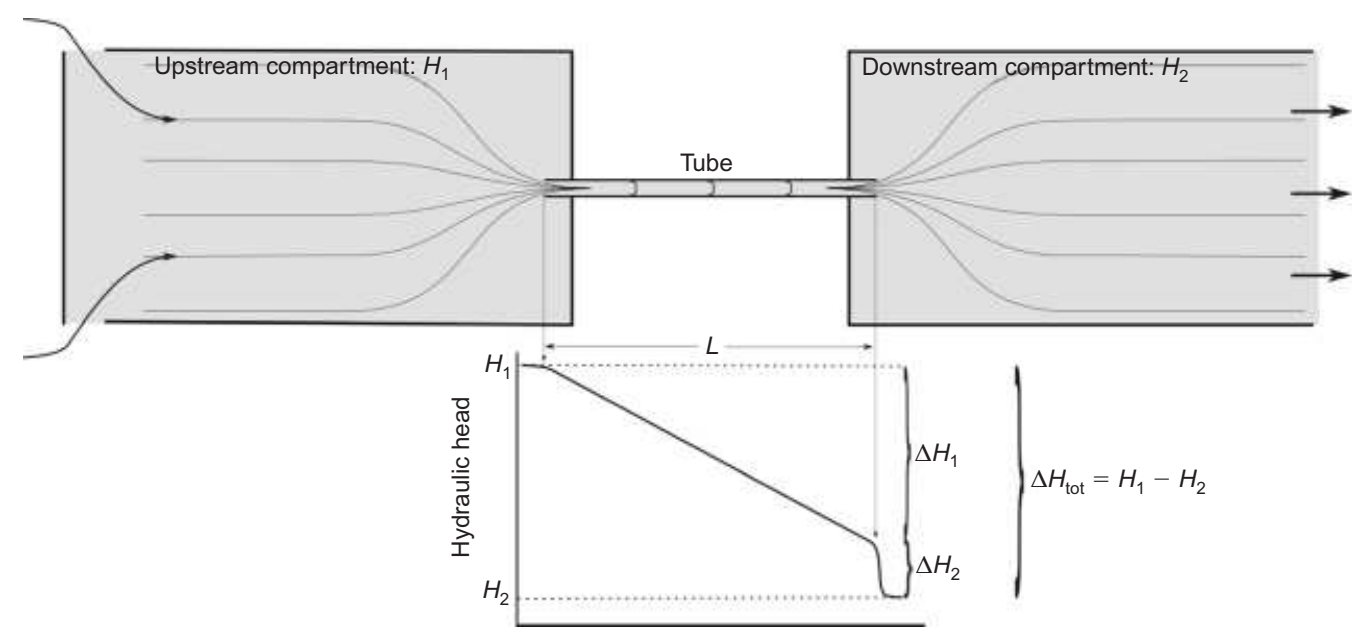

Figure 5. Schematic of a transmissivimeter and associated spatial distribution of head loss 


$$
\Delta H_{\text {tot }}=\left(\lambda \frac{L}{D}+k\right) \frac{8}{D^{4} \pi^{2} g} Q^{2}
$$

Standard transmissivimeters (ASTM D4716-08 or ISO 12958:2010) are small-scale apparatuses at most $0.355 \mathrm{~m}$ long. Consequently, the linear head loss due to friction between the fluid and the tube wall is very limited by the length of the apparatus. This situation is not representative of field conditions where tube lengths significantly greater than $10 \mathrm{~m}$ are often encountered. Singular head losses in a transmissivimeter (other than those due to friction) are localised at the tube outlet. The water path from tube to full downstream tank can be treated as a sudden widening (see Section 3.2). Hydraulic sections are $0.1 \mathrm{~m}^{2}$ for LST and $0.02 \mathrm{~m}^{2}$ for StdT, whereas tube cross-sections are $0.00016 \mathrm{~m}^{2}$ for $\mathrm{D} 20$ and $0.00028 \mathrm{~m}^{2}$ for D25. Thus, the fluid velocities in the tube and in the apparatus are very different, which suggests that singular head losses are non-negligible in the transmissivimeter. However, in the field, singular head losses are actually different from those in the laboratory: (i) water percolates through the wall instead of entering through the entire cross section of the tube, and (ii) water drains in a large unsaturated collector instead of draining into a large saturated tank (the downstream compartment of the transmissivimeter presents a resistance to flow and the concomitant inevitable increase of singular head loss). Therefore, the singular head losses that occur in transmissivimeter tests were evaluated. Because these singular losses do not exist in the field, a better understanding of the various types of head losses can help designers evaluate the accuracy of transmissivity tests.

In Section 5 the two types of losses are compared: the linear losses that are due to friction and therefore dependent on tube length, and the singular losses that depend on the measuring apparatus. The analysis presented is based on a theoretical approach applied to hydraulic data. Finally, the accuracy of the StdT test against the LST test and discharge capacity are discussed.

\section{COMPARING EXPERIMENT WITH THEORY}

In this section, experimental results are compared with the different calculations in order to confirm the theoretical approach. To evaluate the accuracy of the simulations, the parameter $R$ is used, which is defined as the ratio of the calculated value to the measured value for each datum.
Each data set is then judged by the mean $\bar{R}$ (see Table 1). A value of $R$ closer to unity indicates that the theory closely matches experiment.

\subsection{Testing Colebrook's equation for corrugated tubes}

With the experimental results from the wall pressure tap directly plugged into the tube, Colebrook's equation can be tested. To control the accuracy of Serghides' approximate solution to Colebrook's equation, the following equation based on Equation 3 was used

$$
Z=-\left(\frac{1}{\sqrt{\lambda}}\right)-2 \log \left(\frac{\varepsilon}{3.7 D}+\frac{2.51}{\operatorname{Re} \sqrt{\lambda}}\right)
$$

The accuracy of Serghides' solution is confirmed for values of $Z$ close to zero. For all 165 simulations performed for this research, the mean value $\bar{Z}$ was very acceptable $\left(\bar{Z}=4 \times 10^{-8}\right)$. The maximal value was $Z_{\text {max }}=1.54 \times 10^{-6}$. This means that, for the range of roughness, diameter and fluid velocities used, Serghides' solution to Colebrook's equation is accurate and precise.

The tube geometry is now discussed. As mentioned earlier, Colebrook's equation is not expected to be fully applicable to corrugated tubes because they have two different inner diameters and two different types of roughness. To check that Colebrook's equation is valid for corrugated tubes, the head loss was simulated numerically for the different diameters and roughness values and the results were compared with experimental data acquired from a pressure tap directly plugged into the tube. The results of the comparison are presented in Table 2, which gives the mean $\bar{R}$. Recall that the calculated values approach the experimental values as $\bar{R}$ approaches unity.

Table 2 is unequivocal: the calculations significantly underestimate the head loss by a factor 3 to 12 except when using $\mathrm{ID}_{\min }$ as the hydraulic diameter and the corrugation depth (i.e., $\mathrm{ID}_{\max }-\mathrm{ID}_{\min }$ ) as the roughness, in which case the calculations agree very closely with the experimental results for both the D20 and D25 tubes $(\bar{R}$ is respectively 1.03 and 0.98 ). Thus, as expected, the minimal ID value must be used as the hydraulic diameter. This result validates the assumption that the roughness due to corrugation depth $(2.1$ and $2.7 \mathrm{~mm}$ for tubes D20 and $\mathrm{D} 25$, respectively) prevails over conventional surface roughness $(100 \mu \mathrm{m})$. Thus, using the conventional surface roughness in calculations leads to a significant underestimation of head loss. This result seems reasonable

Table 2. Experimental head loss compared with theory for different corrugated-tube geometries. Theory agrees with experiment for $\bar{R}=1$ and departs from experiment for $\overline{\boldsymbol{R}} \neq \mathbf{1}$

\begin{tabular}{|l|l|l|}
\hline $\mathrm{D} 20$ & Conventional roughness: $100 \mu \mathrm{m}$ & Corrugation depth roughness: $2.1 \mathrm{~mm}$ \\
$\mathrm{ID}_{\min }=14.13 \mathrm{~mm}$ & $\bar{R}=0.32$ & $\bar{R}=1.03$ \\
$\mathrm{ID}$ & $\bar{R}=0.24$ \\
& $\bar{R}=0.09$ & \\
$\mathrm{D} 25$ & Conventional roughness: $100 \mu \mathrm{m}$ & Corrugation depth roughness: $2.7 \mathrm{~mm}$ \\
$\mathrm{ID}$ & $\bar{R}=0.98$ \\
$\mathrm{ID}_{\max }=24.16 \mathrm{~mm}$ & $\bar{R}=0.29$ & $\bar{R}=0.10$ \\
\hline
\end{tabular}


because, with such a large difference in scale, the greater roughness would be expected to prevail.

Although $\bar{R} \sim 1$ is obtained when using the corrugation depth for roughness, the average is over the entire range of flow rates. Thus, from these results alone it is not clear that such agreement would occur at every value of flow rate throughout the entire range. To demonstrate that this is indeed the case, Figure 6 shows the calculated head-loss curves plotted with the measured head-loss data. With no adjustable parameters, the calculated curve correctly matches the data over the entire flow rate range.

These results demonstrate that, when using the minimal ID value as the hydraulic diameter and the difference between the maximal ID and the minimal ID as the roughness, Colebrook's equation provides a very accurate description of the discharge capacity of corrugated DTPG tubes.

\subsection{Simulation of head loss obtained in StdT and LST}

After analysing the discharge capacity of corrugated tubes, the second stage of this work involves describing the hydraulic behaviour of an entire DTPG in a transmissivimeter. Recall that, in addition to the frictional linear head loss that occurs in the tube, a singular head loss occurs in a transmissivimeter at the tube outlet. Figure 7 summarises experimental results acquired with the LST and the StdT grouped by tube diameter and length. For each series of experiments, the curve generated by Equation $7\left(\Delta H_{\text {tot }}\right)$ and implemented by Equation 3 (Colebrook's equation) and Equation 6 (singular loss at widening) is presented.

The curves match most data points rather well, which indicates that the calculations can be used to predict head loss with reasonable accuracy. The scatter of the data around the curves is attributed partly to measurement uncertainties but predominantly to the composite aspect of some of the series. For example, the series ' $L=100 \mathrm{~cm}$, D25' groups 48 tests conducted with one, two and four tubes. Despite using the number of tubes to correct both the flow-rate and the difference in fluid velocity between transmissivimeter and tubes, some differences remain and explain the slight scatter. To evaluate the results of the calculation for the various series of measurements, Table 3 uses $\bar{R}$ to compare the calculated head losses with measurement series.

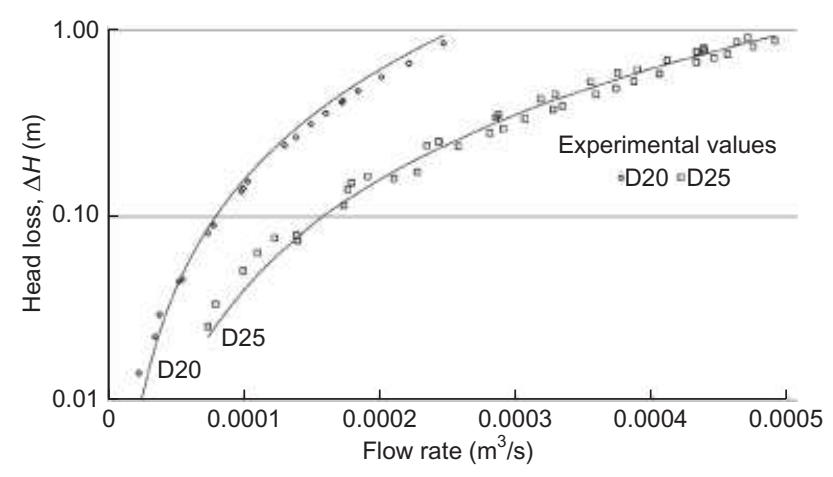

Figure 6. Discharge capacity of tubes. Solid lines are calculated head-loss curves. The slight scatter in the experimental values is due to measurement uncertainty
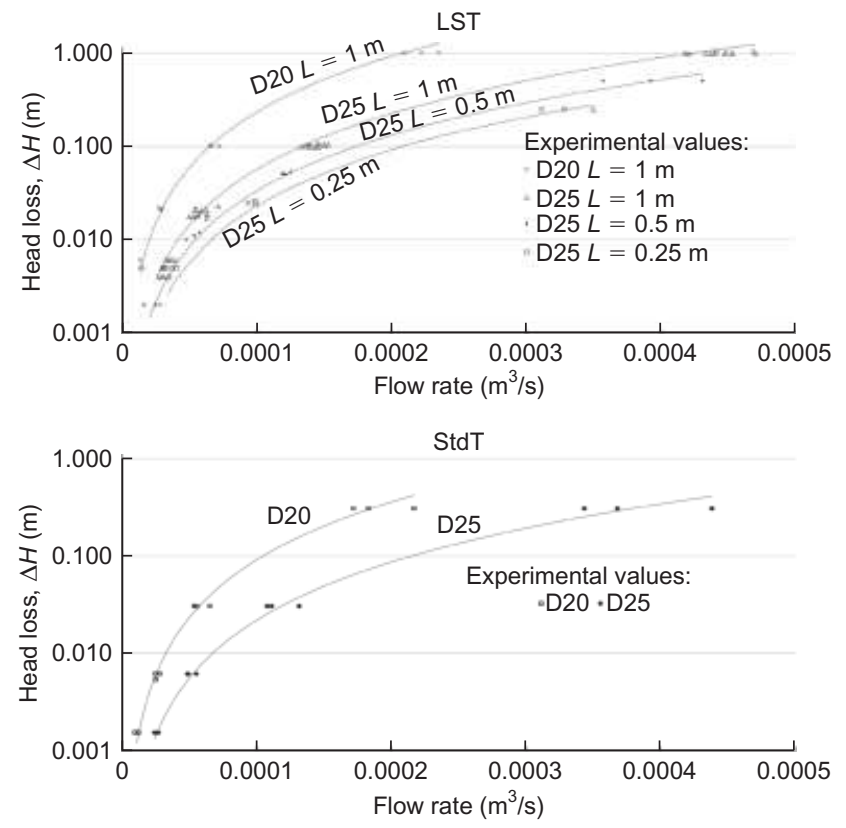

Figure 7. Head loss as a function of flow rate. Points are experimental data and solid lines are calculated curves

Table 3. Statistics to evaluate the accuracy of the calculation

\begin{tabular}{|l|c|c|}
\hline Configuration & $\bar{R}$ & Number of experiments \\
\hline D 20 & 0.96 & 30 \\
D 25 & 1.02 & 82 \\
StdT & 1.00 & 24 \\
LST & 1.01 & 88 \\
LST $L=25 \mathrm{~cm}$ & 0.83 & 12 \\
LST $L=50 \mathrm{~cm}$ & 0.92 & 16 \\
LST $L=100 \mathrm{~cm}$ & 1.07 & 60 \\
Total & 1.00 & 112 \\
\hline
\end{tabular}

The worst value of $\bar{R}(0.83)$ is for a short specimen ( $0.25 \mathrm{~m}$ long), which corresponds to an underestimation of head loss by $17 \%$. Nonetheless, this result is still acceptable because the LST was designed to test large specimens and is not optimised for testing short DTPGs. For appropriate specimen length $(>0.5 \mathrm{~m})$, the simulation precisely describes the experimental results with a mean $\bar{R}$ close to unity.

Thus, to calculate the total head loss in a transmissivimeter, Colebrook's equation and the equation for loss in a sudden widening are appropriate and give satisfactory results. The tube geometry (diameter, roughness, length) determines the intensity of the linear head loss, and the difference in fluid velocity at the outlet determines the singular head loss. Having established a sound theoretical basis to calculate linear and singular head losses, these two types of losses can be compared to determine the relative contribution of each.

\section{DISCUSSION}

Multiscale results from three apparatus reveal the contribution of linear head loss due to the hydraulic property of the 
DTPG and of singular head loss inherent to the methodology of the test. The results are reported in Table 4.

In a StdT the singular head loss reaches $28 \%$ of the total head loss, whereas in a LST the contribution of singular head loss is contained at around $10 \%$. The longer is the DTPG specimen, the lower is the contribution of singular loss. In other words, in a StdT about $25 \%$ of the head loss measured is due to the apparatus and so does not exist in real conditions. Although this singular loss is restricted to the space just around the outlet, it cannot be neglected in a StdT apparatus. With linear head losses contributing less than $75 \%$ of the total head loss, the results of StdT apparatus are questionable.

For the sake of simplicity and as a tentative conclusion, the results in terms of transmissivity are discussed first. The transmissivity, albeit controversial if not correlated to one specific hydraulic gradient, is commonly used to as a guide in designing geocomposites. The results presented herein can help designers understand the impact of transmissivimeters on the transmissivity. Here, transmissivity is defined as the ratio of the flow capacity of a single tube to the hydraulic gradient and so depends on the hydraulic gradient because of non-laminar conditions. Figure 8 and Table 5 summarise the calculated transmissivity of a DTPG as a function of hydraulic gradient and for the different experimental apparatus used to make the measurements. The transmissivity of the DTPG as measured by the LST is equivalent to the intrinsic tube transmissivity. Nonetheless, the transmissivities obtained by the StdT are clearly lower. When measured with the StdT, the DTPG transmissivity is about $15 \%$ lower than the real discharge capacity of the tube.

Table 4. Contribution of singular head loss for different apparatuses

\begin{tabular}{|l|l|c|c|}
\hline ND & Device & Length (m) & $\begin{array}{c}\text { Contribution of } \\
\text { singular head loss } \\
(\%)\end{array}$ \\
\hline D20 & Tube only & 0.7 & 0 \\
& LST & 0.305 & 9 \\
& StdT & 1 & 23 \\
D25 & Tube only & 0.7 & 0 \\
& LST & 0.305 & 11 \\
& StdT & 1 & 28 \\
\hline
\end{tabular}

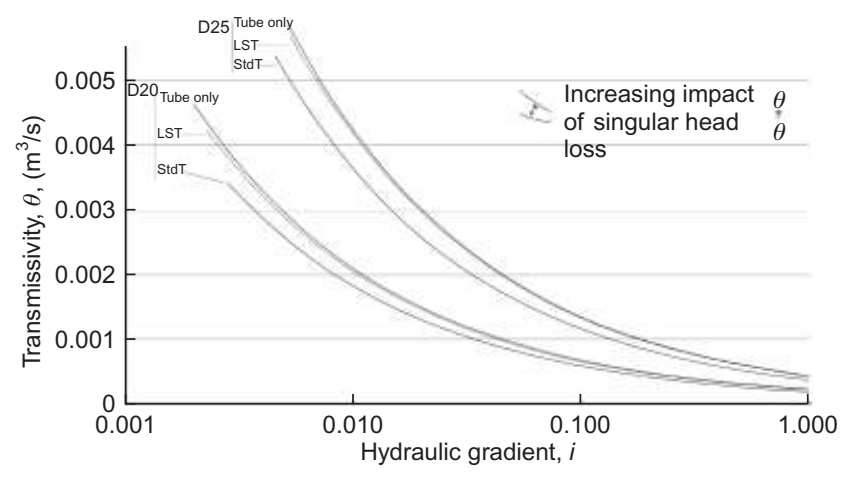

Figure 8. Transmissivity as a function of hydraulic gradient for three different apparatuses
Table 5. Transmissivity for the three different apparatus

\begin{tabular}{|l|l|c|c|c|}
\hline & & $i=0.1$ & $i=0.01$ & $\begin{array}{c}\text { Decrease of } \\
\text { transmissivity } \\
(\%)\end{array}$ \\
\hline D20 & Tube only & $6.73 \times 10^{-4}$ & $2.10 \times 10^{-3}$ & \\
& LST & $6.55 \times 10^{-4}$ & $2.04 \times 10^{-3}$ & 2.5 \\
& StdT & $5.85 \times 10^{-4}$ & $1.82 \times 10^{-3}$ & 13.0 \\
D25 & Tube only & $1.35 \times 10^{-3}$ & $4.24 \times 10^{-3}$ & 1.6 \\
& LST & $1.33 \times 10^{-3}$ & $4.17 \times 10^{-3}$ & 14.1 \\
& StdT & $1.16 \times 10^{-3}$ & $3.64 \times 10^{-3}$ & 14 \\
\hline
\end{tabular}

Normally, standardised tests should ensure an accurate and reliable comparison between the different products because many engineers use the transmissivity for design purposes. Thus, the transmissivity measured via standardised tests should be representative of in-situ conditions (Giroud et al. 2000). However, because of the difference in transmissivity obtained with different apparatuses, the comparison of different geocomposites seems to be compromised. Indeed, other drainage geocomposites exhibit different behaviour from that of DTPGs because the hydraulic capacity is homogeneous across the entire width. For example, geonets have a higher hydraulic section than DTPGs for equivalent transmissivity. The singular head loss at the outlet of a geonet is lower than for a DTPG because of a smaller difference in hydraulic section within the apparatus. Thus, the standard transmissivity test is more representative for geonets than for DTPGs. This study shows the importance of singular head losses in the ASTM test and highlights the drawback of using this test for DTPGs: an accurate comparison between products is impossible.

The standard ISO 12958:2010 states 'the test is intended primarily as an index test but can be used also as a performance test when the hydraulic gradients and specimen contact surfaces are selected by the user to model anticipated field conditions.' The results of the present study indicate that this statement does not apply for DTPGs. From the understanding gained in this study of the variable ratio between the different head losses and the result that transmissivity depends on the apparatus used for measurement, some recommendations for measuring transmissivity can be formulated. First, as mentioned by Faure et al. (1993), a better way to evaluate the in-plane capacity of DTPGs is to directly test the tubes. The discharge capacity may be easily evaluated using the costeffective technique of plugging pressure taps into the tubes. Furthermore, the specimen must be as long as possible. Typical transmissivity measurements made following the standard tests introduce a bias because roughly $25 \%$ of the head loss thus measured is non-existent under field conditions.

\section{CONCLUSION}

An experimental procedure was designed to analyse the hydraulic properties of a DTPG on three successive scales, from a single tube to a representative DTPG surface. 
Three different apparatuses were used to make these measurements: (i) a standard ASTM transmissivimeter (StdT), (ii) a new apparatus in which pressure taps are plugged directly into tubes to find their intrinsic drainage capacity (because the tubes make the major contribution to the overall discharge capacity), and (iii) a large-scale transmissivimeter (LST) used to test a surface representative of a DTPG (i.e., $1 \mathrm{~m}$ square).

Next, the experimental data were used to calibrate a theoretical approach based on well-known hydraulic equations. The relationship between hydraulic conductivity and hydraulic gradient expressed by the model agrees well with the results of hydraulic conductivity tests. This numerical simulation of head loss compares three measuring apparatuses and reveals the differing contributions of linear and singular head losses. The results show that the standard ASTM test underestimates the transmissivity of DTPGs. The difference between the discharge capacity of a tube alone and the results of standard measurements attains $14 \%$ because a significant fraction of head loss is introduced by the StdT. This head loss is singular (localised at the tube outlet) and reaches $28 \%$ of the total head loss for the D25 specimen. Thus, the results indicate that the protocol and the measuring apparatus dictated by the standard ASTM test have an unacceptable impact on the measurement results.

This study shows the importance of singular head losses in the ASTM test and demonstrates the problem of testing DTPGs with this standard: the criterion that the StdT results be representative is not satisfied for DTPGs. Although results obtained with the LST show that this apparatus is better suited to obtain the real transmissivity of DTPGs because it uses a specimen length of $1 \mathrm{~m}$, some singular head loss also occurs in the LST apparatus. Thus, to correctly characterise DTPGs, the geotextile and the tubes (the base elements of DTPGs that provide most of the discharge capacity) must be evaluated separately. To ensure that the results are representative of real conditions, tubes should be directly tested by plugging pressure taps through the tube wall. This simple and cost-effective technique makes it possible to accurately quantify the discharge capacity of DTPGs.

\section{NOTATION}

Basic SI units are given in parentheses.

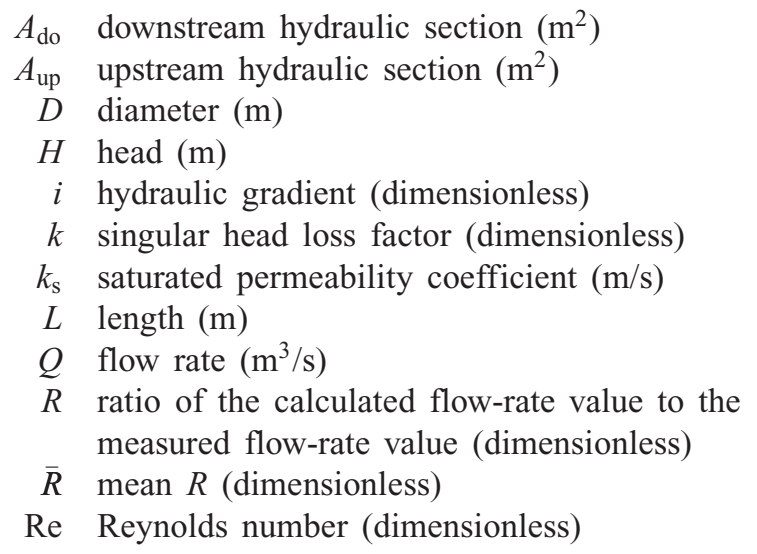

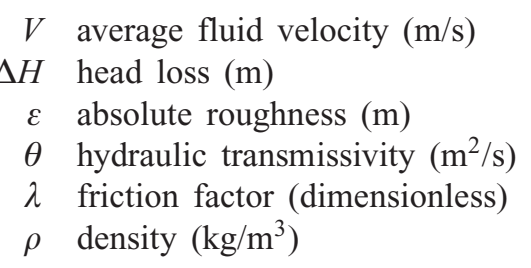

\section{Abbreviations}

ASTM American Society for Testing and Materials

DTPG drain-tube planar geocomposite

ID inner diameter

ISO International Organization for Standardization

LST large-scale transmissivimeter

ND nominal diameter

StdT standard ASTM transmissivimeter

\section{REFERENCES}

ASTM D4716-08. Standard Test Method for Determining the (In-plane) Flow Rate per Unit Width and Hydraulic Transmissivity of a Geosynthetic Using a Constant Head. ASTM International, West Conshohocken, PA, USA.

Bordier, C. \& Zimmer, D. (2000). Drainage equations and non-Darcian modelling in coarse porous media or geosynthetic materials. Journal of Hydrology, 228, No. 3-4, 174-187.

Bourgès-Gastaud, S., Blond, E. \& Saunier, P. (2012). Applicability of drain tube planar geocomposites for heap leach pads. Proceedings of the 2nd Pan American Geosynthetics Conference, GeoAmericas 2012, Lima, Peru (CD-ROM).

Brkić, D. (2011). Review of explicit approximations to the Colebrook relation for flow friction. Journal of Petroleum Science and Engineering, 77, No. 1, 34-48.

Colebrook, F. C. (1939). Turbulent flow in pipes, with particular reference to the transition region between the smooth and rough pipe laws. Journal of the Institution of Civil Engineers, 11, No. 4, $133-156$.

Edwards, M. F., Jadallah, M. S. M. \& Smith, R. (1985). Head losses in pipe fittings at low Reynolds numbers. Chemical Engineering Research and Design, 63, No. 1, 43-50.

Faure, Y. H., Matihard, Y., Brochier, P. \& Suryolelono, K. (1993). Experimental and theoretical methodology to validate new geocomposite structures for drainage. Geotextiles and Geomembranes, 12, No. 5, 397-412.

Fester, V. G., Kazadi, D. M., Mbiya, B. M. \& Slatter, P. T. (2007). Loss coefficients for flow of Newtonian and non-Newtonian fluids through diaphragm valves. Chemical Engineering Research and Design, 85, No. 9, 1314-1324

Giroud, J. P., Zornberg, J. G. \& Zhao, A. (2000). Hydraulic design of geosynthetic and granular liquid collection layers. Geosynthetics International, 7, No. 4-6, 285-380.

Giroud, J. P., Gourc, J. P. \& Kavazanjian, E. Jr. (2012). Laminar and nonlaminar flow in geosynthetic and granular drains. Geosynthetics International, 19, No. 2, 160-182.

ISO (2010). BS EN ISO 12958:2010. Geotextiles and Geotextile-Related Products. Determination of Water Flow Capacity in Their Plane. BSI, London, UK.

Kandlikar, S. G., Schmitt, D., Carrano, A. L. \& Taylor, J. B. (2005). Characterization of surface roughness effects on pressure drop in single-phase flow in minichannels. Physics of Fluids, 17, No. 10, 100606.

Koerner, R. (1997). Geocomposites. In Designing with Geosynthetics. Prentice Hall, Englewood Cliffs, NJ, USA.

Moody, L. F. (1944). Friction factors for pipe flow. Transactions of the ASME, 66, No. 8, 671-684.

Nikuradse, J. (1933). Laws of flow-in rough tubes. VDI-Forschungsheft, 361 (in German).

Palmeira, E. M. \& Gardoni, M. G. (2002). Drainage and filtration 
properties of non-woven geotextiles under confinement using different experimental techniques. Geotextiles and Geomembranes, 20, No. 2, 97-115.

Reynolds, O. (1883). An experimental investigation of the circumstances which determine whether motion of water shall be direct or sinuous and of the law of resistance in parallel channels. Philosophical Transactions of the Royal Society, London, 174, No. 35, 935-982.

Romeo, E., Royo, C. \& Monzón, A. (2002). Improved explicit equations for estimation of the friction factor in rough and smooth pipes. Chemical Engineering Journal, 86, No. 3, 369-374.

Saunier, P., Ragen, W. \& Blond, E. (2010). Assessment of the resistance of drain tubes planar drainage geocomposites to high compressive loads. Proceedings 9th International Conference on Geosynthetics, Guarujá, SP, Brazil, vol. 3, p. 1131.

Serghides, T. K. (1984). Estimate friction factor accurately. Chemical Engineering (New York), 91, No. 5, 63-64.
Sonnad, J. R. \& Goudar, C. T. (2006). Turbulent flow friction factor calculation using a mathematically exact alternative to the Colebrook-White equation. Journal of Hydraulic Engineering, 132, No. 8, 863-867.

Thual, O. (2010). Hydrodynamique de l'Environnement. Les Éditions de l'École Polytechnique, Palaiseau, France, chapter 3 (in French).

Touze-Foltz, N. (2002). The influence of non-uniform transmissivity visà-vis hole location. Geotextiles and Geomembranes, 20, No. 4, $263-277$.

van der Sluys, L. \& Dierickx, W. (1987). The applicability of Darcy's law in determining the water permeability of geotextiles. Geotextiles and Geomembranes, 5, No. 4, 283-299.

Zimmel, E., Li, M. \& Youngblood, J. (2011). Effects of specimen size in transmissivity tests of biplanar geonets and geocomposites. Proceedings Geo-Frontiers 2011: Advances in Geotechnical Engineering, Dallas, TX, USA, 2011, pp. 2203-2212.

The Editor welcomes discussion on all papers published in Geosynthetics International. Please email your contribution to discussion@geosynthetics-international.com by 15 December 2013. 